\title{
Menswear, a fashion trend for women in the 1970s (How sociopolitical events of the 1970's result in the projection of menswear for women in the movie Annie Hall) \\ Moghadaseh Rouhi Ardeshiri \\ University of Bologna, Italy
}

\begin{abstract}
Fashion of the twentieth century beginning from "The Belle Époque" in 1900, and closing the period by the minimalistic style of the nineties, is divided into decades to better study the most dominant style of each. In this essay the sociopolitical events of the 1970s, the achievements of the feminism movements, and cultural confines set before genders had been under focus to determine the influence of the current events in the community on fashion. In parallel to this impressible aspect, fashion has a mutual relationship with cinema. In this survey the effort was to clarify the influential traffic among three angles of Cinema, Fashion and Society, concentrated on the Woody Allen's 1977 movie, Annie Hall as the case for study. The aim here was to describe how this movie having an overall soul of the fashion throughout the decade could initiate a new style by taking its core ideas from the ground ongoing social flows.
\end{abstract}

Keywords: Fashion, Society, Transvestism, Cross-dressing, Annie Hall

\section{Introduction}

\section{A brief history of the 1970 s}

Social and political effects on what we know of fashion of the 1970s, in the studies and discussions over the decade, is more based and focused in the United States and United Kingdom; which had been under worldwide concentrations and pioneers in social changes. Regarding women's communities, in 1973 as a result of a sequential of feminist activities in the US, eventually they could win to grasp the advantage of legalization of the abortion. By 1975 the movement was able to make the government consider issues as Sex Discrimination and Equal Pay Acts in UK. By the end of the decade, Margaret Thatcher becomes the first woman prime minister of Britain.

This was the period for the pivot of changes and achievements in women's liberation activities, black movements, worker's movements and gay liberations. Lesbians regarding to their rights demanding were most result-fully active in the 70 s among other feminist activists in US.

In the first half of the decade, US was engaged in the Vietnam War, ending in 1975 with the fall of Saigon. Meanwhile, several anti-war attempts were taken place against Washington policies. Increasing the soul of opposition and resistance throughout the society.

In a worldwide glance, the world was exploding from wars and fundamental political changes. The 1970s decade started by widening the war with Vietnam in an order by Richard Nixon to invade Cambodia, and later the presidential change in Egypt, in 1971 India and Pakistan headed into war, terrorist attack in Munich Olympic Games in 1972, where eleven Israel athletes were killed, fights between Israel and Arab states in 1973, thereupon the Watergate scandal, Nixon resigned in 1974 and became the first president to do so, Gerald Ford was sworn in as the next president, while in 1976 Jimmy Carter was elected as president of US, in 1979 the revolution in Iran turned the Kingdom into the Islamic Republic, resulting in another recession in the world in terms of the second oil shortage, in the same year Saddam Hussein became president of Iraq, Margaret Thatcher became the prime minister of Britain, following to these, the seizing of the US embassy in Tehran and holding hostages by the militants; and invasion of Soviet troops to Afghanistan in support to establishing another communism.

It was in the same world and at the same era that some great influential technological inventions were taking place. Mobile phones, Microsoft incorporations and Apple computers are born in this decade and were first introduced; all of which are still today on top of our everyday means of technology.

\section{Feminism in the 1970 s}

Liberty, the most desired right for women, from all the constraints on their gender, from being subjugated and being considered the subordinated gender or "the second sex" as Simone de Beauvoir discusses in her book, drove women in the United States of the 1970s to fight for the ratification of the ERA (Equal Right Amendments). They made Protests, demonstrations and went on strikes in demand for equality. "Women's liberation shifted boundaries, crossed zones, made politics into something else" (Rowbotham 1983, 4).

"It was within the context of the emergent feminism of the 1970s, however, that the principle of hope found its fullest and most radical expression." (Bammer 1991, 51) It is noteworthy that these movements have their origins and basis in the pursuing activities of the previous decades, where all the emerging and prosperous events of the new decade has been initially established.

As Bammer explains, women in the American Civil Rights movement, had been fighting not only for their freedom and equal rights, but also against political inefficiency in counteracting poverty, racism and taking an effective role in anti-war movements. All these, while their own basic right (for granted to be given to every individual) was under a huge question, as being divided in terms of gender to a subordinate category. 
The new postwar generations of women got the credo that only through taking an effective part in the political activities they could procure the right to choose their own way of life, and stand against the current flow of simulating of fates. They felt the need to change.

In 1973 following the kept on activities serving women's right demands, in a landmark decision on "the Roe v. Wade" case, the United States Supreme Court declares that abortion is a constitutional right. Women could finally see hopes for arriving a time "when motherhood would become an option to be chosen rather than a destiny to be accepted." (Taylor Allen 2005, 209)

In their efforts to receive the equal rights socially and professionally to a man, this era provided grounds to eventually prove this. In1973 Billy Jean King beats Bobby Riggs in the "Battle of the Sexes" tennis match, resulting in the public acceptance of women's tennis.

It increasingly became a decade for emergence and growth of women's magazines which considerably helped the flourishing and recognition of women artists and poets.

\section{Women's Fashion in the 1970s}

Tradition makes uniformity in dressing according to each gender, no matter the status, even if some try to differentiate themselves by means of material or adding decorations or accessories to an already for granted framework of a clothes as to distinguish themselves from other people or other social classes, still the silhouette of the figures for each gender would be united. The 1970s is often recognized as a decade for individuality, a decade to abandon the rules and conventions. Fashion at this era is seeking forms to diminish the gap of genders, and in turns differentiating the clothing in their designs according to their own aesthetics and needs. This flowing line of individualism is a concept Tom Wolfe took advantage of in his essay for the 1976 issue of the New York Magazine, entitled "The "Me" Decade and the Third Great Awakening". In his essay Wolfe explains how Americans in the 1970s are redirected from the 1960s social values and how in this period individual goals overtake the collective benefits. A similar template is spontaneously flowed to the world of fashion, through the funiculus, connecting it to the society.

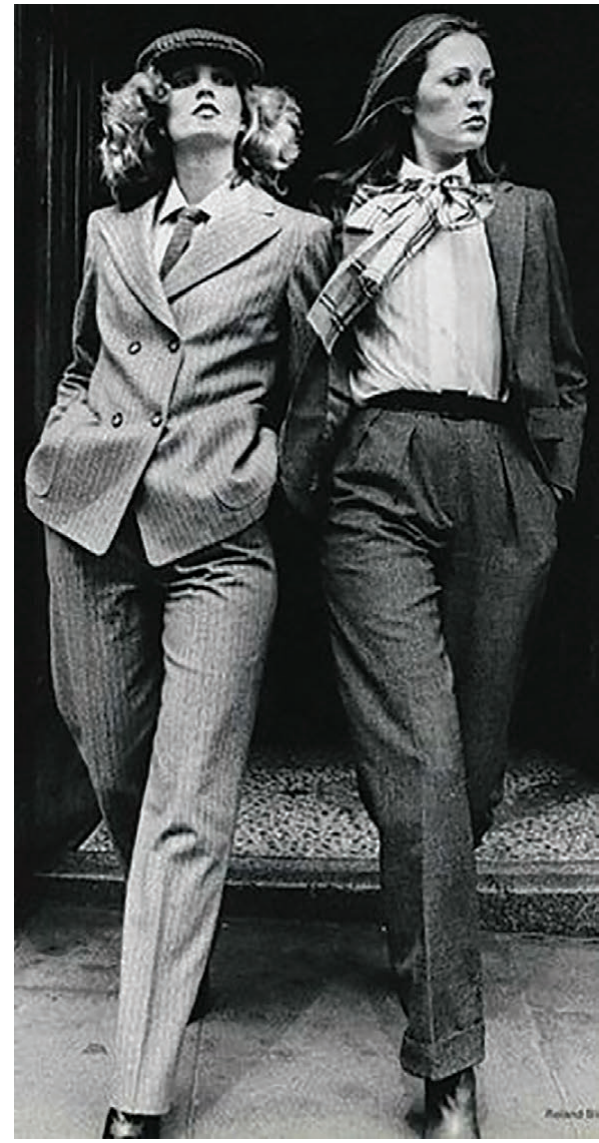

Figure 1 - 1970's Menswear inspired by Annie Hall. (Source of the image: Pinterest.com)

"Changes in fashion through the twentieth century have brought enormous changes in the physical treatment and conceptualization of women's bodies. These transformations in the way women appeared were both influenced by and contributed to changing notions of womanhood." (McNeil 2009, 150)"By the 1970s, the importance of the individual and his or her emotional needs was a major theme in architecture and design" (Lutyens \& Hislop 2009, 7) Considering fashion, in the years between 1970 and 1973, obviously the overlapping years with the previous decade, women are more up to catch up on hippies' style, use of bright color dresses, Mexican peasant blouses, frayed jeans, ponchos, bellbottoms, ...everything that would take the 60 s style to its extremes and exaggerated form would be most welcomed in the 70s.

But the most common style for both genders was the use of flare pants and platform shoes, which was at the time an extreme pose for women, to publicly appear 
in pants, in everyday life. An overall comparison of women's most common fashion in the 1960s and the 1970s, notifies a revolution, a huge change, although there still exists remains of the effects of the previous decades in the following ones. But during these years women, along with the other social rules, could establish a new atmosphere for them where traditional expectations from any feminine creature would no more serve as her inevitable fate. This became a chance for women to choose becoming a mother, a time for economic independence of women as they started working. Although not every clothing style should be considered as fashion, as we know fashion has its "exclusive ambiguous definitions", but it cannot be underestimated the roles of these progressions in women's rights demands in their dressing styles. The similarity of the commonest style of this decade for both genders is due to this regard.

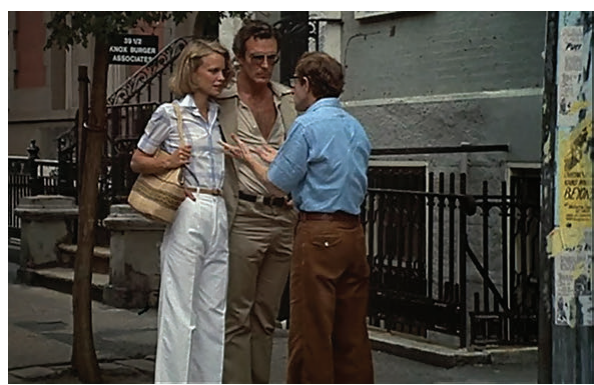

Figure 2 -A scene from the movie: Annie Hall (1977) in which a couple in the street are dressed in the same style.

Women to be taken seriously in society or at work must bring outwards their "animus" layers, while for men to shine in the world of masculine competitors and to differentiate themselves it's more likely to reveal their "anima". And by this they differentiate themselves by transgressing the conventions.

Hot pants, flare pants, leisure suits, platform shoes, bell bottoms, ponchos, gauchos, capes, every transformation and exaggeration of the 60 s, imitating music artists and popular movies; Afro hairstyle, Farrah Fawcett hairstyle, long shaggy hair... It all made a fantasy world in parallel to the real world seriously undergoing wars and reformations. Covering all the body with accessories as chokers, dog collars, handcrafted ornaments. Counteractions between designers and people, nothing of the total look remains. Fashion was to make a bricolage of every available piece. Jeans became the commonest wear for both men and women.

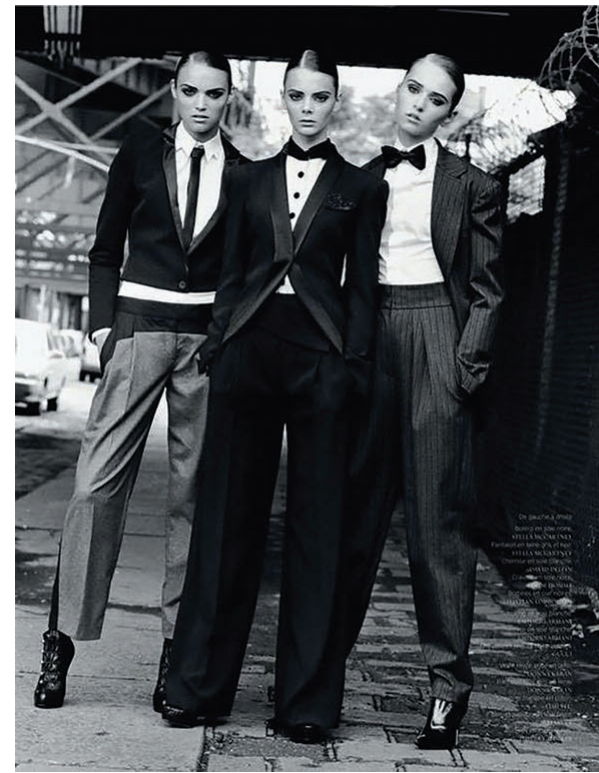

Figure 3 - Cross-Dressing Pictorials - The Multi-Model Editorial, 'New Faces' in French Revue De Modes (GALLERY) (Source of the image: Pinterest.com)

Convenience was a criteria to design women's clothing in this decade, to support the idea of providing comfort for the busy modern woman.

By the late 1970s, color almost disappeared. Light brown, grey, khaki, black and white were the dominant colors by 1979 (obviously noticed in Annie Hall). It seems that extremely bright tones of the early years were too much to resist more than a decade.

\section{Dress and Identity}

\section{Transvestism or Cross-Dressing}

"A woman must not wear men's clothing, nor a man wear women's clothing, for the LORD your God detests anyone who does this." (Deuteronomy 22:5)

In the 1970s fashion loses some of its obsession in dividing the individuals by gender, and is more inclined towards genderless designs. For both females and males the dominant style of this period was a tight shirt and lousy trousers. In fact women of the 1970s with their backgrounds in experiencing the previous epochs in style and dressing, found a different outfit to support their ideologies and demands for liberty and equality, which showcased their look in some degrees of "cross-dressing". To determine the term in the following, necessary is to mention the presence of a diversity of reasons for people across history to dress as the opposite gender. 


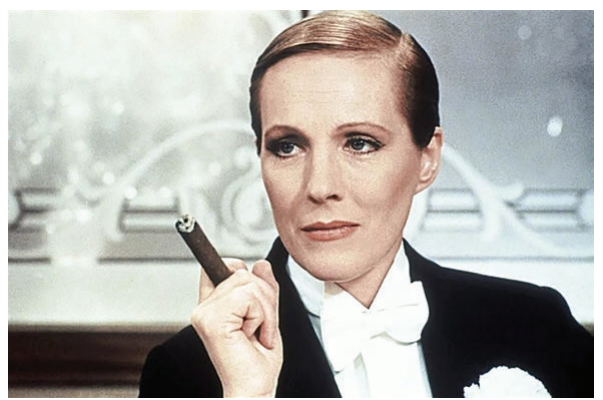

Figure 4 - Victor/Victoria (1982), directed by Blake Edwards. After her failed singing audition, Julie Andrews disguises in menswear, pretending to be a gay Polish female impersonator.

In the movie The Danish girl (2015) Einar is cross dressing in order to uncover his gender identity, hidden under the sexual appearance, to embody Lili. $\mathrm{He}$ believes that the emergence of the masculine sex in him is a mistake, but searching for an identity in Annie Hall (1977) has nothing to do with physical sex, but the gender behavior resulting from it and her social status as a female. This comes to prove once again the ever submitted idea of masculinity as the embodiment of power and dominance while it represents the submissive role of femininity. Speaking of cross-dressing or transvestism the first subject rising is the male's part of the concept. Female dressing in menswear would not be considered as problematic. Charlotte Suthrell explains that "Gender lies at the intersection of culture and biology".

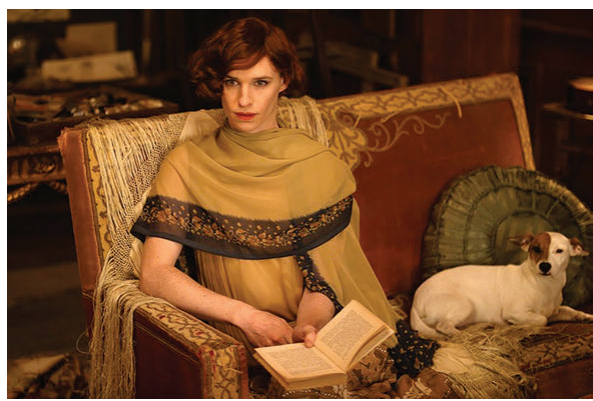

Figure 5 - The Danish girl (2015), directed by Tom Hooper Einar Wegener discovers his life-long identification as a woman during his posing as a female model for his painter wife.

What makes men to give up of their "born in power" status and cross-dress to the submissive gender is to be studied through an interdisciplinary discussion and is not the subject to this study.

Historically women used cross-dressing in order to achieve a social goal, as experiencing the freedom and safety, participating in activities forbidden to females. "George Sand deliberately adopted male clothing in order to engage fully in Parisian literary society because it allowed her to behave as a man, with all the associated freedoms of masculinity." (Suthrell 2004, 8); or even at times not with an aim to disguise themselves but to feel the comfort out of the tight waist, narrow skirt dresses by dressing the masculine power. Suthrell describes transvestism as a more general word than cross-dressing. It includes not only dressing as the opposite gender (cross-dressing) but also as their own gender while seeking the purpose of creating a new identity. The desired identity to get permission to go through doors they could not pass without the new dressing style. Dress here makes a new character and requires relevant traits to work.

"Transvestism provides an eye-opening link in this research between two theoretical fields - material culture and gender - because it lies at the intersection of the two. For many decades now, sex and gender have been popular and well-studied topics and the implications, which certainly affect our lives in a multiplicity of ways, both directly and indirectly, have been of particular interest to academic research and to feminism." (Suthrell 2004, 14)

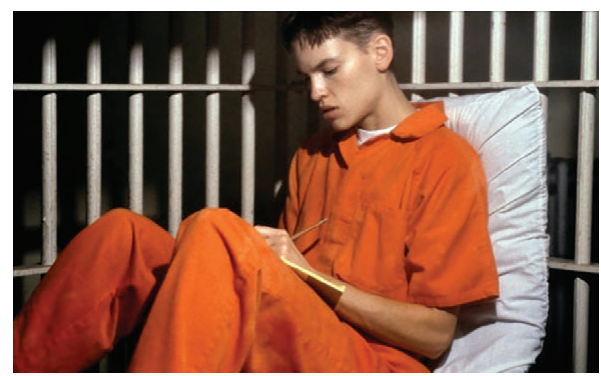

Figure 6 - Boys Don't Cry (1999), directed by Kimberly Peirce. The story of a young man discovering to be a transgender.

The way we dress attaches us to groups and categories in the society, it has the power to build up an identity independent of the content. That is where transvestism comes to birth. Clothes here provide an added identity to the body within it. Hides the granted self and puts on expose a chosen one. Clothes reveal aspects of our roots and belongings, give information about us and communicate prior to words. This is more obvious in a more traditional society where the rules for dress codes are stricter and dress is not a mere outfit but a sign. In a more modern society the freedom of choices makes the interpretation of the signals from different clothing more complicated and diverse, but the indicative role of the dress would remain the same. Suthrell argues that the existence of a gender based dress code is necessary to the creation of the concept of cross-dressing. In this case dress shapes a "visual identificatory code" in the nonverbal communication system. 


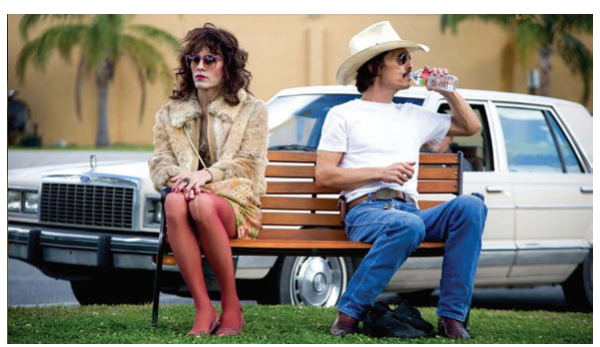

Figure 7 - Dallas Buyers Club (2013), directed by JeanMarc Vallée. A combination of concepts such as AIDS, Drug addiction and transsexuality in Texas 1985.

As a result, although throughout history and regardless of geography, there has always been conventional gender norms for dress codes, it is believed that masculinity and femininity must be more about biology rather than their social roles and status. Even so, it is indisputable that there has always been certain conventions in associating a dress to a specific gender; Ferris explains that men who dress in women's clothing are so "out of place" and become "monstrous".

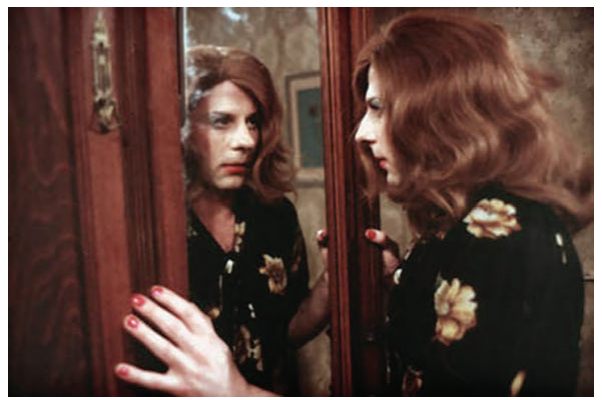

Figure 8 - The Tenant (1976), directed by Roman Polanski. Trelkovsky (Roman Polanski) finds himself changing and transforming into the shape as well as the destiny of the dead woman who used to live in the same apartment he recently moved into, before committing suicide.

"Disruptions of the semiotics of dress by men and by women were not read in the same way. For a man, wearing women's dress undermined the authority inherently belonging to the superior sex and placed him in a position of shame." (Ferris 2005, 23-24)

"For women the significance of cross-dressing is different. In the polemical literature women who crossdressed were less often accused of sexual perversion than of sexual incontinence, of being whores. This was in part because the discursive construction of woman in the Renaissance involved seeing her as a creature of strong sexual appetites needing strict regulation. Her sexual desire was both a mark of her inferiority and a justification for her control by men." (Ferris 2005, 24-25) This theory led to centuries of being under control of men and therefore being considered as an ever inferior gender.

\section{Menswear in Annie Hall (1979)}

It has been said that the main idea of the costume designing for Annie comes from the own clothes of Diane Keaton. True or not costume designers will always remain the most responsible ones for the outfits of the characters in a movie. Ruth Morley could create the look of the intellectualized 1970s' for Dian Keaton. In most of the scenes Keaton is appearing in men's dresses gracefully and delicately changed and fitted on her; feminized menswear! Annie, unlike some other movies' female characters is not crossdressing to fake the opposite gender.

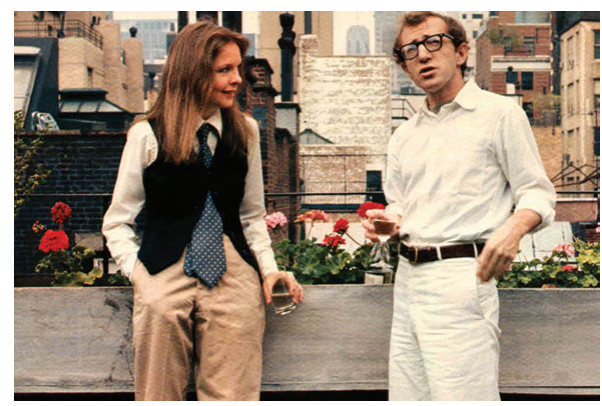

Figure 9 - Annie Hall (1977) Annie dressed in a menswear with touches of femininity.

In the history of Cinema or to be more comprehensive, in the history of performing arts cross-gender acting was an ever-attached trait. In the ancient Greek theater, in the Elizabethan theater or in the eastern counterparts: the Japanese kabuki, cross gender acting- here men acting as women- was not only a common trend but also a law force. For women it was for a long time illegal to work or do acting. But this attitude also might be the theme of the plot, where men or women cross dress in serving to the narrative. William Shakespeare uses the same plot in "The merchant of Venice" "Twelfth night" and "As you like it" to enable the female characters in order to obtain an active logical role in the closed society of the time. To develop women that are influential in their lives and of their surrounding ones, Shakespeare had to dress them as male. So that the society would trust them, accept their argumentations and reasoning.

The status of women in the 70 s and of course in the years the movie was being produced, the late 70s, is best described in the character of Annie, where she is seeking her own personality. Initially Annie tries to find herself and her professional life and career in Alvy. At the commencement of their relationship she thinks she's not smart enough for him. She's jumping from one field to another in order to find her"self" and Alvy is the guideline. Gradually by getting unlinked to the relying man, Alvy Singer, she is coming to a point where she doesn't crave getting married as was the traditional expectation of the role of a woman, as a wife (housewife) or a more extreme further role as a mother. She makes choices. The society at the time 
was changing, commencing to give women the new rights while contradictorily, merely sending them the underlying message to take the traditional path. Alvy pushes Annie to take university courses, grabs her subconscious into his own world, but then backlashes her individuality. Loves her independency and even asks for it, but suffers from the same trait.

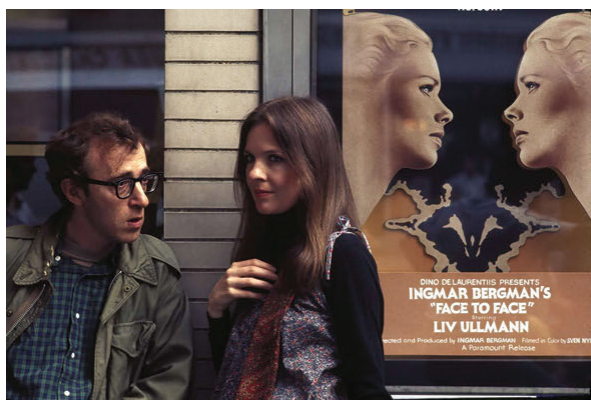

Figure 10 - Annie Hall (1977). The evolution of personality and individuality in the character of Annie becomes a turning point in her relationship with Alvy.

All this is conveyed in parallel with the clothing style of Annie. We don't go deep into the character of Annie, although the movie is under her name but was not made to be so, as that was a later attribution to the movie. Initially it was coming with different suggestions for the title by Allen and Brickman and also by hiring an advertising agency. Finally Allen chose the title Annie Hall after five screening tests with different titles in regard to the commercial marketing of the movie. It all explains the reason we still remain in the superficiality of the female character, but we go deep inside the soul of Alvy, from his childhood to his adulthood worries and dreams. He addresses us as audience in several parts and explains some of his ideologies and through this hook he holds our sympathy close to him. The name of the movie is now transforming from a character to a "Question" in Alvy's mind, Annie Hall is Alvy's problem in matter of his relationships. There is no significant regular evolution in the way Annie is dressing, her looks at first glances are made to catch attention. By using a combination of both gender's outfits and developing her own style, Annie is portraying a woman who is in search for an identity but still unable to make it without the helps from a man. Alvy not only is the one with great role in her attitudes towards education, readings and ways of thinking, but also gives her financial supports, ready to pay her apartment's rent (to avoid her moving into his apartment), paying for her therapy...However she gradually becomes more and more independent both economically and emotionally until the moment she can easily reject Alvy's marriage solution for their relationship. Morley is using a mixture of masculine and feminine characteristics in her design for Annie's costume to best show her in between the two poles. Her costumes are so obviously distinct and so well settled that created a fashion trend in the outer world.

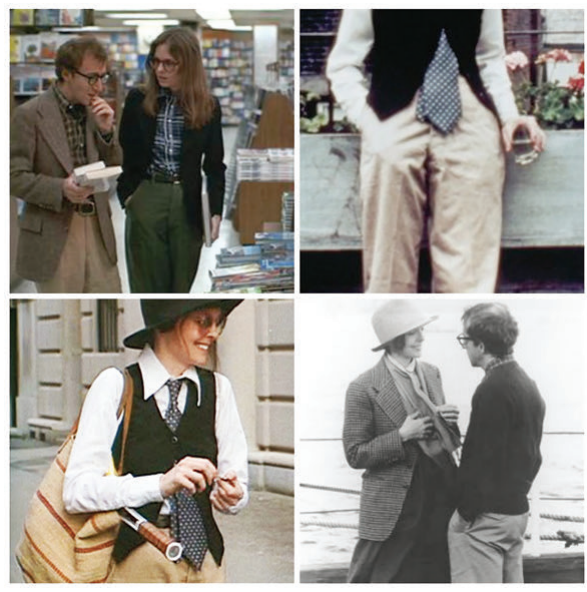

Figure 11 - Annie Hall (1977). Scenes from the film showcasing the costume style designed for Annie.

\section{Conclusion}

To conclude my discussion, starting with a brief description of fashion in the 1970 s, noteworthy is that the family units were endangered by liberation movements as of gays' and women's. Women were fighting for economic independency and equality in the payments with a view to achieve a more essential right, "to choose". The ground to break traditions and stereotypes was already prepared to lead in a diversity in the fashion world. Having no specific rule in clothing, made the individuality and exclusivity of fashion for everyone. The decade started with colorful dresses with extreme bright tones, and ended in an almost colorless outfits.

The confines and obstacles in front of an individual in his or her purpose to get a specific permission to enter a forbidden world have been the main reason of transvestism over centuries. And when the desired world was of the opposite gender came the term cross-dressing to describe the act. It was in 1970s that cross-dressing was no more as a cover. Women were starting to wear trousers. Jeans became common for both genders. Femininity was distinguishable even covered in menswear. The fashion of the time was reflected in the costume designs of the movies such as Saturday Night Fever (1977) and Annie Hall (1979).

Annie Hall became one of the most influential movies of the time and the following decades. The movie is from 1979, having the overall impact of the era. The freedom sought by women over years is observed in a symbolic way in Annie's costume. She does not circumscribe herself in the conventional gender based dress codes, however her outfits are not fully percent affiliated to a determined gender. She makes her own style with the idea having its basis in the dominant ideology in the human communities; Liberty, not only in the selection of the pieces but also in the flappy style of the coats and trousers. Women of this time were choosing how to wear and who to be. 


\section{Bibliography}

Bammer, Angelika. 1991. Partial Visions: Feminism and Utopianism in the 1970s. London: Routledge.

Baudot, Francois. 1999. A Century of Fashion. London: Thames \& Hudson.

Entwistle, Joanne. 2000. The Fashioned Body. Cambridge: Polity Press.

Ferris, Leslie, ed. 2005. Crossing the Stage: Controversies on Cross-Dressing. London: Routledge.

Lutyens, Dominic and Kirsty Hislop. 2009. 70s Style \& Design. London: Thames \& Hudson Ltd.

McNeil, Peter, ed. 2009. Fashion: Critical and Primary Sources, (Vol 4: The twentieth Century to Today). Oxford: Berg.

Munich, Adrienne, ed. 2011. Fashion in Film. Indiana University Press.

Rowbotham, Sheila. 1970. "Alexandra Kollontai: Woman's Liberation and Revolutionary Love" Spokesman (June): 27-32.

Rutter, Virginia and Pepper Schwartz. 2000. The Gender of Sexuality. Lanham: AltaMira Press.

Steele, Valerie, ed. 2010. The Berg Companion to Fashion. Oxford: Berg.

Suthrell, Charlotte. 2004. Unzipping Gender: Sex, Cross-Dressing and Culture. Oxford: Berg.

Taylor Allen, Ann. 2005. Feminism and Motherhood in Western Europe, 1890-1970. New York: Palgrave Macmillan.

\section{Filmography}

Annie Hall. 1977. directed by woody Allen. United States Boys Don't Cry. 1999. directed by Kimberly Peirce. United States.

Dallas Buyers Club. 2013. directed by Jean-Marc Vallée. United States

The Danish girl. 2015. directed by Tom Hooper. United Kingdom, United States.

The Tenant. 1976. directed by Roman Polanski. France Victor/Victoria. 1982. directed by Blake Edwards. United Kingdom, United States. 